\title{
Hematology and Serum Biochemistry Values in Five Captive Finless Porpoises (Neophocaena phocaenoides)
}

\author{
Masahiko KASAMATSU1)*, Kazuhiro HASEGAWA ${ }^{1)}$, Ikuo WAKABAYASHI ${ }^{1)}$, Atsushi ${ }^{12 K O}{ }^{1)}$ and \\ Masami FURUTA ${ }^{1)}$
}

1) Marine Biological Laboratory, Toba Aquarium, 3-3-6 Toba, Toba, Mie 517-8517, Japan

(Received 5 September 2011/Accepted 8 May 2012/Published online in J-STAGE 23 May 2012)

ABSTRACT. Hematological and serum biochemical values in five captive finless porpoises (Neophocaena phocaenoides) were examined, and abnormalities of aspartate aminotransferase, alanine aminotransferase, lactate dehydrogenase and $\gamma$-glutamyltransferase were determined in a male finless porpoise. The numbers of white and red blood cells in pregnant female porpoises were significantly lower than those in nonpregnant ones $(P<0.05)$. Significantly higher values of serum creatinine were observed in summer when compared with the values in winter $(P<0.01)$. Abnormalities of hepatic enzymes could improve with administration of ursodeoxycholic acid and a hepatic hydrolysate drug.

KEY WORDS: abnormalities of hepatic enzymes, finless porpoises, hematology, serum biochemistry.

doi: 10.1292/jvms.11-0407; J. Vet. Med. Sci. 74(10): 1319-1322, 2012

The finless porpoise (Neophocaena phocaenoides) is a small member of the toothed whales (Odontoceti) and is listed in Appendix I of the Convention on International Trade in Endangered Species (CITES) along with all other cetaceans $[10,13]$. In Japan, finless porpoises have been housed in six aquariums including Toba Aquarium. Data for hematological and biochemical values in marine mammals are essential, because they are used for health management of the animals in aquariums. Seasonal and reproductive physiological variations in serum biochemical parameters were found in captive bottlenose dolphins and harbor seals $[11,15-17]$. It is important to know seasonal and physiological changes in hematological and serum biochemical values in the captive finless porpoise, although little is known about seasonal and reproductive physiological variations in the captive finless porpoise.

The objectives of this study were to provide hematological and serum biochemical values including seasonal and reproductive variations in captive finless porpoises at Toba Aquarium. A suspected case with hepatic diseases is also described in this report.

Five captive finless porpoises, 2 adult females that were approximately 9 years old, 2 adult males that were approximately 10 years old and a male that was 2 years old, that showed normal behavior, good appetite and normal rectal temperature were used in this study. The captive porpoises were housed at Toba Aquarium in Toba, Mie, Japan. All 5 porpoises had been in captivity for at least 2 years and were being used for exhibition and research. The daily diet of each porpoise was frozen whole Japanese jack mackerel

\footnotetext{
*Correspondence to: Kasamatsu, M., Marine Biological Laboratory, Toba Aquarium, 3-3-6 Toba, Toba, Mie 517-8517, Japan. e-mail: masahiko@ivory.plala.or.jp

(C)2012 The Japanese Society of Veterinary Science
}

(Trachurus japonicus). Each porpoise was supplemented with a multivitamin tablet (5M26 Vita-Zu tablet, Mazuri, IN, U.S.A.).

Blood examinations were performed at monthly intervals as part of a health management program and were collected in the morning over $12 \mathrm{hr}$ after a last feeding. Samples were taken from the tail fluke of the porpoises by using a serum separator and an ethylenediaminetetraacetic acid (EDTA) tube. Complete blood counts (CBC) were determined by an automated analyzer (CELL-DYN 3200, Abbott Laboratories, Abbott Park, IL, U.S.A.). Leukocyte differentiations were detected by microscopic examination of Giemsastained blood smears. The serum biochemistries were examined by using an automated analyzer (TBA-c16000, Toshiba Medical Systems, Tochigi, Japan). Serum protein electrophoresis (SPEP) was conducted with an analyzer (AES 320, Olympus, Tokyo, Japan). Serum progesterone concentration was determined by electrochemiluminescence immunoassays using an analyzer (Modular Analytics E170, Roche Diagnostics, Indianapolis, IN, U.S.A.).

One of the 10-year-old male finless porpoises with high aspartate aminotransferase (AST), alanine aminotransferase (ALT), lactate dehydrogenase (LDH) and $\gamma$-glutamyltransferase (GGT) activity levels from April to September 2007 was diagnosed with a subclinical hepatic disorder, and all data for hematology and serum biochemistry from this porpoise were excluded from the statistical analysis. A 2-year-old male porpoise had markedly higher alkaline phosphatase (ALP) levels, and ALP data from this porpoise were excluded from the analysis. Results of blood examinations are presented as means \pm standard deviation (SD). Values of $\mathrm{CBC}$ and serum biochemistry in male, nonpregnant female and pregnant female porpoises were analyzed by using one-way analysis of variance (ANOVA) with Tukey HSD post hoc comparisons. Associations between serum aminotransferase activities and triglyceride 
Table 1. Hematological and serum biochemical values of captive finless porpoises at Toba Aquarium

\begin{tabular}{|c|c|c|c|c|c|c|}
\hline & \multicolumn{2}{|c|}{ Male } & \multicolumn{2}{|c|}{ non-Preg } & \multicolumn{2}{|c|}{ Preg } \\
\hline & Samples No. & Mean \pm SD & Samples No. & Mean \pm SD & Samples No. & Mean \pm SD \\
\hline PCV (\%) & 30 & $46.9 \pm 1.7^{\mathrm{d})}$ & 12 & $46.2 \pm 1.2$ & 14 & $45.4 \pm 1.5$ \\
\hline $\operatorname{RBC}\left(10^{4} / \mathrm{m} l\right)$ & 30 & $529.7 \pm 40.1^{\mathrm{d})}$ & 12 & $515.3 \pm 26.7^{\mathrm{c})}$ & 14 & $491.8 \pm 22.2$ \\
\hline $\mathrm{Hb}(\mathrm{g} / \mathrm{d} l)$ & 30 & $16.6 \pm 0.7$ & 12 & $16.6 \pm 0.5$ & 14 & $16.3 \pm 0.6$ \\
\hline $\operatorname{MCV}(\mathrm{f} l)$ & 30 & $89.0 \pm 6.0$ & 12 & $89.8 \pm 2.8$ & 14 & $92.4 \pm 2.6$ \\
\hline $\mathrm{MCH}(\mathrm{pg})$ & 30 & $31.6 \pm 2.9$ & 12 & $32.3 \pm 1.0$ & 14 & $33.2 \pm 1.0$ \\
\hline $\operatorname{MCHC}(\mathrm{g} / \mathrm{d} l)$ & 30 & $35.5 \pm 1.3$ & 12 & $36.1 \pm 0.8$ & 14 & $36.0 \pm 0.7$ \\
\hline $\mathrm{WBC}(/ \mu l)$ & 30 & $\left.4440.0 \pm 1307.9^{\mathrm{c}}\right)$ & 12 & $\left.4825.0 \pm 1029.7^{\mathrm{d}}\right)$ & 14 & $3514.3 \pm 802.7$ \\
\hline Stb $(/ \mu l)$ & 30 & $48.5 \pm 57.4$ & 12 & $33.4 \pm 60.4$ & 14 & $35.1 \pm 45.3$ \\
\hline $\operatorname{Seg}(/ \mu l)$ & 30 & $1754.4 \pm 830.7^{\mathrm{c})}$ & 12 & $1542.2 \pm 615.5$ & 14 & $907.4 \pm 314.1$ \\
\hline $\operatorname{Eos}(/ \mu l)$ & 30 & $728.6 \pm 501.7$ & 12 & $902.8 \pm 461.9$ & 14 & $572.6 \pm 155.0$ \\
\hline Bas $(/ \mu l)$ & 30 & NO & 12 & NO & 14 & NO \\
\hline Ly $(/ \mu l)$ & 30 & $2213.1 \pm 664.1$ & 12 & $2364.2 \pm 766.8$ & 14 & $1832.9 \pm 764.0$ \\
\hline Mo $(/ \mu l)$ & 30 & $118.0 \pm 129.8$ & 12 & $88.4 \pm 30.4$ & 14 & $37.7 \pm 35.6$ \\
\hline AST (IU/l) & 30 & $254.4 \pm 59.7$ & 12 & $239.8 \pm 49.9$ & 14 & $224.1 \pm 18.9$ \\
\hline $\operatorname{ALT}(\mathrm{IU} / l)$ & 30 & $43.5 \pm 15.0$ & 12 & $42.8 \pm 13.6$ & 14 & $43.5 \pm 9.3$ \\
\hline LDH (IU/l) & 30 & $275.8 \pm 51.3^{\mathrm{b}, \mathrm{d})}$ & 12 & $221.3 \pm 23.4$ & 14 & $203.2 \pm 24.0$ \\
\hline $\operatorname{ALP}(\mathrm{IU} / l)$ & 18 & $486.3 \pm 144.6$ & 12 & $418.2 \pm 144.4$ & 14 & $390.5 \pm 137.7$ \\
\hline GGT (IU/l) & 30 & $25.2 \pm 5.0$ & 12 & $23.6 \pm 3.8$ & 14 & $24.1 \pm 2.8$ \\
\hline $\mathrm{CPK}(\mathrm{IU} / l)$ & 30 & $147.8 \pm 33.5$ & 12 & $146.5 \pm 30.9$ & 14 & $136.7 \pm 28.3$ \\
\hline $\mathrm{TP}(\mathrm{g} / \mathrm{d} l)$ & 30 & $6.8 \pm 0.3$ & 12 & $6.9 \pm 0.4$ & 14 & $6.8 \pm 0.3$ \\
\hline Albumin $(\mathrm{g} / \mathrm{d} l)$ & 30 & $4.56 \pm 0.20^{\mathrm{c})}$ & 12 & $4.44 \pm 0.30$ & 14 & $4.35 \pm 0.27$ \\
\hline Globulin $(\mathrm{g} / \mathrm{d} l)$ & 30 & $2.28 \pm 0.20^{\mathrm{b}, \mathrm{c})}$ & 12 & $2.51 \pm 0.30$ & 14 & $2.44 \pm 0.14$ \\
\hline $\mathrm{A} / \mathrm{G}$ & 30 & $2.01 \pm 0.16^{\mathrm{b}, \mathrm{d})}$ & 12 & $1.78 \pm 0.14$ & 14 & $1.78 \pm 0.16$ \\
\hline Sodium $(\mathrm{mEq} / l)$ & 30 & $155.7 \pm 2.3$ & 12 & $156.6 \pm 3.4$ & 14 & $156.5 \pm 2.1$ \\
\hline Potassium $(\mathrm{mEq} / l)$ & 30 & $4.6 \pm 0.3^{\mathrm{c})}$ & 12 & $4.8 \pm 0.4^{\mathrm{d})}$ & 14 & $4.3 \pm 0.5$ \\
\hline Chloride $(\mathrm{mEq} / \mathrm{l})$ & 30 & $117.6 \pm 2.2^{\mathrm{b}, \mathrm{d})}$ & 12 & $120.3 \pm 2.4$ & 14 & $120.4 \pm 2.4$ \\
\hline Calcium $(\mathrm{mg} / \mathrm{d} l)$ & 30 & $9.9 \pm 0.3^{\mathrm{b})}$ & 12 & $9.6 \pm 0.3^{\mathrm{c})}$ & 14 & $9.9 \pm 0.2$ \\
\hline Phosphorus (mg/d $l$ ) & 30 & $5.6 \pm 0.6^{\mathrm{b}, \mathrm{c})}$ & 12 & $5.0 \pm 0.3$ & 14 & $5.1 \pm 0.3$ \\
\hline T-bili $(\mathrm{mg} / \mathrm{d} l)$ & 30 & $0.1 \pm 0.0$ & 12 & $0.1 \pm 0.0$ & 14 & $0.1 \pm 0.0$ \\
\hline BUN $(\mathrm{mg} / \mathrm{d} l)$ & 30 & $50.1 \pm 4.2$ & 12 & $50.7 \pm 3.1$ & 14 & $48.8 \pm 1.8$ \\
\hline $\mathrm{CRE}(\mathrm{mg} / \mathrm{d} l)$ & 30 & $0.93 \pm 0.18^{\mathrm{d})}$ & 12 & $0.77 \pm 0.10^{\mathrm{d})}$ & 14 & $1.10 \pm 0.16$ \\
\hline Glucose $(\mathrm{mg} / \mathrm{d} l)$ & 30 & $148.2 \pm 15.3$ & 12 & $135.3 \pm 31.9$ & 14 & $143.5 \pm 17.1$ \\
\hline $\mathrm{T}-\mathrm{chol}(\mathrm{mg} / \mathrm{d} l)$ & 30 & $230.7 \pm 31.4^{\mathrm{d})}$ & 12 & $225.8 \pm 15.8^{\mathrm{d})}$ & 14 & $195.2 \pm 8.8$ \\
\hline $\mathrm{TG}(\mathrm{mg} / \mathrm{d} l)$ & 30 & $42.3 \pm 14.3^{\mathrm{a})}$ & 12 & $54.3 \pm 12.9$ & 14 & $49.5 \pm 8.8$ \\
\hline $\operatorname{PRO}(n \mathrm{~g} / \mathrm{m} l)$ & ND & ND & 12 & $3.61 \pm 6.00^{\mathrm{d})}$ & 14 & $22.84 \pm 9.70$ \\
\hline
\end{tabular}

Non-preg, nonpregnant porpoise; Preg, pregnant porpoise; PCV, packed cell volume; RBC, red blood cells; Hb, hemoglobin; MCV, mean corpuscular volume; $\mathrm{MCH}$, mean corpuscular hemoglobin; $\mathrm{MCHC}$, mean corpuscular hemoglobin concentration; WBC, white blood cells; Stb, bands neutrophils; Seg, segmented neutrophils; Eos, eosinophils; Bas, basophils; Ly, lymphocytes; Mo, monocytes; AST, aspartate aminotransferase; ALT, alanine aminotransferase; LDH, lactate dehydrogenase; ALP, alkaline phosphatase; GGT, $\gamma$-glutamyltransferase; CPK, creatinine phosphokinase; TP, serum total protein; A/G, albumin/globulin ratio; T-bili, direct bilirubin; BUN, blood urea nitrogen; CRE, creatinine; T-chol, total cholesterol; TG, triglyceride; PRO, progesterone. NO, not observed; ND, not determined. a) $(P<0.05)$ and b) $(P<0.01)$, significantly different from the value for nonpregnant porpoises; $\mathrm{c})(P<0.05)$ and $\mathrm{d}(P<0.01)$, significantly different from the value for pregnant porpoises.

concentrations in the porpoises were examined by using Pearson's correlation coefficient ( $r$ ). A $P$-value less than 0.05 was considered to be statistically significant.

Hematological and serum biochemistry values for captive finless porpoises are shown in Table 1. Pregnant females had significantly lower levels for packed cell volume (PCV), red blood cells (RBC), white blood cells (WBC) and segmented neutrophils than those in males $(P<0.01)$. Significantly lower levels for $\mathrm{RBC}$ and $\mathrm{WBC}$ were found in pregnant females than in nonpregnant females $(P<0.05)$.

Nonpregnant females had significantly lower levels of
LDH, albumin/globulin ratio (A/G), calcium and phosphorus $(P<0.01)$, and significantly higher levels of globulin, chloride and triglyceride than those in males $(P<0.05)$. Pregnant females had significantly lower levels of LDH, albumin, $\mathrm{A} / \mathrm{G}$, potassium, phosphorus and total cholesterol $(P<0.05)$, and significantly higher levels of globulin, chloride and creatinine than those in males $(P<0.05)$. Except for potassium, calcium, creatinine and total cholesterol, no significant differences were found in any serum biochemical parameters between pregnant and nonpregnant porpoises.

Serum creatinine levels in the porpoises in summer (from 
June to August) were significantly higher than those in winter (from December to February) $(P<0.01)$. A 2-year-old male porpoise was juvenile and had markedly higher serum ALP levels $(1,678.6 \pm 176.8 \mathrm{IU} / l)$.

The mean serum AST, ALT and LDH activities in samples from individual porpoises obtained in January were 357.2, 60.8 and $294.4 \mathrm{IU} / l$, respectively, and were significantly increased compared with samples from other month groups (Fig. 1) $(P<0.05)$. There was no significant increase in the level of GGT in January. Serum triglyceride concentrations in samples from individual porpoises began increasing in January, peaked in February and were decreased in May 2007.

One of the male finless porpoises with high levels of AST and ALT activities from May to August was considered to have a subclinical hepatic disorder. The serum AST, ALT, LDH and GGT activity levels in the male porpoise began increasing in April and peaked in July (AST, $686 \mathrm{IU} / l$; ALT, $298 \mathrm{IU} / l$; LDH, $475 \mathrm{IU} / l$; and GGT, $57 \mathrm{IU} / l)$. The male was treated with ursodeoxycholic acid (100 mg, BID, PO) and a hepatic hydrolysate drug (proheparum, 1 tab, BID, PO) between April 2007 and January 2009, and then the serum biochemical parameters improved (AST, $272 \mathrm{IU} / l$; ALT, 42 $\mathrm{IU} / l$; LDH, $307 \mathrm{IU} / l$; and GGT, $30 \mathrm{IU} / l$ ).

Hematology and serum chemistry are essential tools for assessing health states in humans and animals. It is known that many hematology and serum chemistry parameters vary with sex, age, season, and physiological state [2]. Hematological data in the porpoises were similar to those for captive and free-ranging bottlenose dolphins $[1,4,6,7]$. Female bottlenose dolphins had a significantly higher PCV than males [6]. No statistically significant differences were found in any hematologic parameters between pregnant and nonpregnant dolphins [6]. However, in the present study, RBC and WBC counts in pregnant porpoises were significantly lower than those in nonpregnant porpoises. As was found in pregnant porpoises, that blood levels of RBC, PCV and hemoglobin were significantly decreased in pregnant rats compared with those in nonpregnant rats [12]. Progressive normocytic anemia in pregnant dogs has been reported. It has been thought that the anemia of pregnant dogs is caused by hemodilution due to an increased plasma volume [5]. Anemia in pregnant dolphins has not been reported. The decreases of PCV and RBC counts observed in the present study may be related to fetus growth, although the mechanisms of decreased PCV and RBC counts were unclear.

Data for several serum biochemical parameters including fibrinogen, lipid and lipoprotein in captive and free-ranging dolphins have been reported [1, 4, 6-9, 14, 17]. The values reported here for serum biochemical parameters in the porpoises were, with few exceptions, higher for the levels of LDH and phosphorus and lower for the levels of globulin, chloride and triglyceride in sera from male porpoises than those from females, in general agreement with values previously reported for captive and free-ranging bottlenose dolphins. It is thought that changes in serum aminotransferase activities have to be carefully monitored in routine serum biochemical examinations because serum AST values in
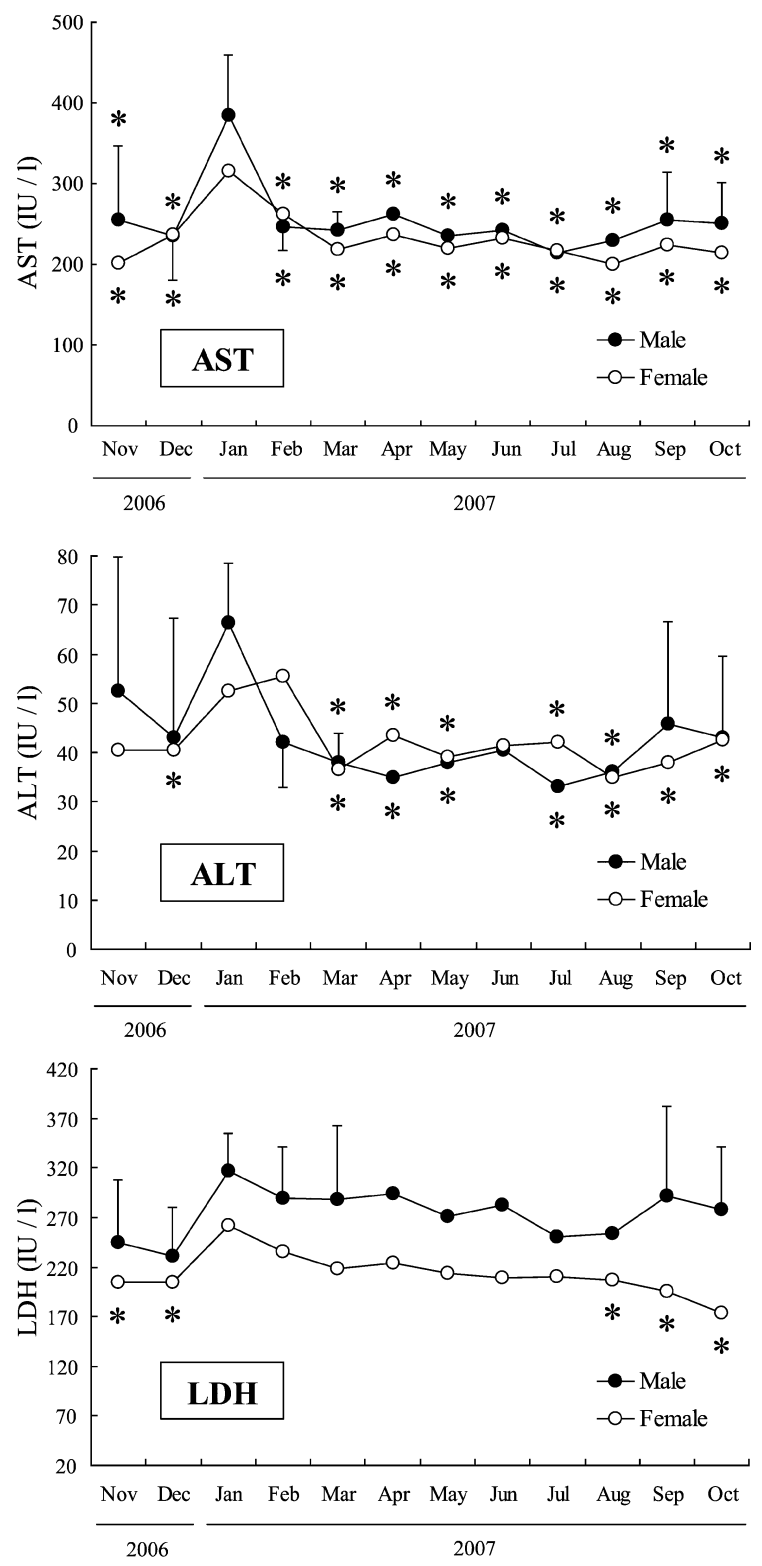

Fig. 1. Kinetics of serum biochemical findings of captive finless porpoises. AST, aspartate aminotransferase; ALT, alanine aminotransferase; LDH, lactate dehydrogenase. Data were expressed as the mean $\pm \mathrm{SD}$. The numbers of samples assayed were 2 or 3. Asterisks indicate a significant difference $(P<0.05)$ from the mean for the values in January.

porpoises are comparatively higher than those in bottlenose dolphins.

Seasonal differences in hematological and serum biochemical parameters have been reported in wild beluga whales and bottlenose dolphins [7, 14]. A study on captive bottlenose dolphins also showed significantly higher creatinine levels in adult animals in summer than in winter $[7,17]$. Creatinine is present in the muscle, and there is a slow catabolism of creatine at a rate directly proportional 
to muscle mass. The quantities of creatinine excreted are closely related to body muscle mass and metabolic rate of the animal [17]. The data in the present study are similar to the results reported by Hall et al. (2007) and Terasawa et al. (2002), suggesting that these changes in serum creatinine are thought to be due to variations in the muscle mass.

Serum hepatic enzyme tests in terrestrial mammals are grouped into those that indicate hepatocellular injury or repair. ALT, produced by the liver, appears to be liver-specific in bottlenose dolphins, Pacific white-sided dolphins and pilot whales $[3,4]$. In some cetaceans with hepatic disease, serum AST activity will return to normal more rapidly than serum ALT activity [4]. In the present study, it was found that episodic increases in serum ALT and AST activities occurred in January and that an increase in serum triglyceride concentrations occurred between January and April after an increase in aminotransferase activities. The results of the present study showing that serum ALT and AST activities in January were significantly increased suggest that there is hepatocellular injury in the porpoises. Venn-Watson (2008) reported that dolphins with episodic increases in serum aminotransferases were more likely to have a higher prevalence of hyperlipidemia compared with healthy controls [18]. The findings in previous study are consistent with the increase in serum triglyceride concentration subsequent to increases of serum aminotransferase activities and the significant correlations between serum aminotransferase activities and serum triglyceride concentrations (vs AST, $\mathrm{r}=0.17, P<0.01$; vs ALT, $\mathrm{r}=0.84, P<0.01)$ in the porpoises. Clinical signs in captive dolphins are limited to mild decreases in appetite. In cases of increasing serum ALT and AST activities in captive dolphins without clinical symptoms such as decreases in appetite, progressive and careful hematological examinations are needed. It was suggested that administration of ursodeoxycholic acid and a hepatic hydrolysate drug decreased serum aminotransferase activities and was effective in the porpoise with a subclinical hepatic disorder.

ACKNOWLEDGMENTS. The authors thank the staff of Toba Aquarium (Akitoshi Hida, Harumasa Ashikari, Naoki Kawaguchi, Sayori Noguchi, Yukari Oka, Yoshihiro Ishihara, Yoshihito Wakai and Yuske Shimizu) for their assistance in blood sampling. The authors also thank Dr. Hajime Nagahata and Dr. Hidetoshi Higuchi for their helpful advice in the preparation of this manuscript.

\section{REFERENCES}

1. Asper, E. D., Cornell, L. H., Duffield, D. A., Odell, D. K., Joseph, B. E., Stark, B. I. and Perry, C. A. 1990. Hematology and serum chemistry values in bottlenose dolphins. pp. 479-485. In: The Bottlenose Dolphin (Leatherwood, S. and Reeves, R. R. eds.), Academic Press, San Diego.

2. Boily, F., Beaudoin, S. and Measures, L. N. 2006. Hematology and serum chemistry of Harp (Phoca groenlandica) and Hooded seals (Cystoohora cristata) during the breeding season, in the Gulf of St. Lawrence, Canada. J. Wildl. Dis. 42: 115-132. [Medline]

3. Bossart, G. D. 1984. Suspected acquired immunodeficiency in an Atlantic bottlenosed dolphin with chronic-active hepatitis and lobomycosis. J. Am. Vet. Med. Assoc. 185: 1413-1414. [Medline]

4. Bossart, G. D., Reidarson, T. H., Dierauf, L. A. and Duffield, D. A. 2001. Clinical pathology. pp. 383-436. In: The CRC Handbook of Marine Mammal Medicine, Second Edition. (Gulland, F. M. D. and Dierauf, L. A. eds.), CRC Press, Baca Raton.

5. Concannon, P. W. 1986. Canine pregnancy and parturition. Vet. Clin. North Am. Small Anim. Pract. 16: 453-475. [Medline]

6. Goldstein, J. D., Reese, E., Reif, J. S., Varela, R. A., Mcculloch, S. D., Defran, R. H., Fair, P. A. and Bossart, G. D. 2006. Hematologic, biochemical, and cytologic findings from apparently healthy Atlantic bottlenose dolphins (Tursiops truncatus) inhabiting the Indian River Lagoon, Florida, USA. J. Wildl. Dis. 42: 447-454. [Medline]

7. Hall, A. J., Wells, R. S., Sweeney, J. C., Townsend, F. I., Balmer, B. C., Hohn, A. A. and Rhinehart, H. L. 2007. Annual, seasonal and individual variation in hematology and clinical blood chemistry profiles in bottlenose dolphins (Tursiops truncatus) from Sarasota Bay, Florida. Comp. Biochem. Physiol. A Mol. Integr. Physiol. 148: 266-277. [Medline] [CrossRef]

8. Kasamatsu, M., Kawauchi, R., Tsunokawa, M., Ueda, K., Uchida, E., Oikawa, S., Higuchi, H., Kawajiri, T., Uchida, S. and Nagahata, H. 2009. Comparison of serum lipid compositions, lipid peroxide, $\alpha$-tocopherol and lipoproteins in captive marine mammals (bottlenose dolphins, spotted seals and West Indian manatees) and terrestrial mammals. Res. Vet. Sci. 86: 216-222. [Medline] [CrossRef]

9. Kasamatsu, M., Tsunokawa, M., Taki, M., Higuchi, H. and Nagahata, H. 2001. Serum lipid peroxide and $\alpha$-tocopherol concentrations and superoxide dismutase activity in captive bottle-nosed dolphins. Am. J. Vet. Res. 62: 1952-1956. [Medline] [CrossRef]

10. Kasuya, T. 1999. Finless porpoise Neophocaena phocaenoides (G. Cuvier, 1829). pp. 411-442. In: Handbook of Marine Mammals: The Second Book of Dolphins and The Porpoises (Ridgway, S. H. and Harison, R. eds.), Academic Press, London.

11. Kuiken, T. 1985. Influences of diet, gestation, and age on haematology and plasma chemistry of the harbour seal, Phoca vitulina. Aquat. Mamm. 11: 40.

12. LaBorde, J. B., Wall, K. S., Bolon, B., Kumpe, T. S., Patton, R., Zheng, Q., Kodell, R. and Young, J. F. 1999. Haematology and serum chemistry parameters of the pregnant rat. Lab. Anim. 33: 275-287. [Medline] [CrossRef]

13. Reeves, R. R. and Leatherwood, S. 1994. Dolphins, Porpoises and Whales. In: An 1994-1998 Action Plan for The Conservation of Cetaceans, IUCN, Gland.

14. St Aubin, D. J., De Guise, S., Richard, P. R., Smith, T. G. and Geraci, J. R. 2001. Hematology and plasma chemistry as indicators of health and ecological status in beluga whales, Delphinapterus leucas. Arctic 54: 317-331.

15. Terasawa, F., Arai, T., Tokura, T. and Ohshita, I. 2008. Fibrinogen concentrations in captive bottlenose dolphins during pregnancy. J. Vet. Med. Sci. 70: 1277-1279. [Medline] [CrossRef]

16. Terasawa, F. and Kitamura, M. 2005. Hyperlipemia of captive bottlenose dolphins during pregnancy. J. Vet. Med. Sci. 67: 341-344. [Medline] [CrossRef]

17. Terasawa, F., Kitamura, M., Fujimoto, A. and Hayama, S. 2002. Seasonal changes of blood composition in captive bottlenose dolphins. J. Vet. Med. Sci. 64: 1075-1078. [Medline] [CrossRef]

18. Venn-Watson, S., Smith, C. R. and Jensen, E. D. 2008. Assessment of increased serum aminotransferases in a managed Atlantic bottlenose dolphin (Tursiops truncatus) population. J. Wildl. Dis. 44: 318-330. [Medline] 